\title{
STUDI KOMPARASI MODEL PARAMETRIK DAN NON-PARAMETRIK DALAM ESTIMASI EFISIENSI TEKNIS PERKEBUNAN KARET RAKYAT DI SUMATERA SELATAN
}

\author{
Comparison Study of Parametric and Non-Parametric Models in Estimating Technical \\ Efficiency of Smallholders's Rubber in South Sumatra \\ Lina Fatayati SYARIFA* \\ Pusat Penelitian Karet, Jln Raya Palembang - Pangkalan Balai KM 29, Sembawa \\ Banyuasin 30593 Sumatera Selatan \\ *Email : lina_fsy@yahoo.com
}

Diterima : 21 Juni 2020 / Disetujui : 7 Agustus 2020

\begin{abstract}
This study was aimed to determine the estimation of technical efficiency applying both parametric and non-parametric methods since both of them had inherent limitations and advantages. Therefore, this study carried out comparison analyses among the three i.e. the Stochastic Frontier Analysis, Data Envelopment Analysis (DEA), and Bootstrap $D E A$ on data of 380 rubber smallholders in South Sumatra. Results of stochastic frontier analysis indicated that the mean technical efficiency score of sampled farms was 0.72 , indicating that rubber farms in this study were not fully efficient. Meanwhile, the data envelopment analysis (DEA) which did not account for randomness was applied; the mean technical efficiency estimates was 0.80 , indicating that technical efficiency estimates under DEA were overestimated. The limitation of DEA was overcome by applying Bootstrap $D E A$. Under Bootstrap DEA, the mean technical efficiency was reduced to 0.76, which was closer to the mean technical efficiency of SFA. This was because bootstrap $D E A$ had produced confidence interval and bias corrected efficiency estimates of DEA. The difference in the performance among these models could be attributed to the assumption that technical efficiency estimates under DEA approach depend only on farmer's inefficiency effects, whereas technical efficiency estimates under the parametric approach depend on farmer's inefficiency and other factors outside of farmers' control.
\end{abstract}

Keywords: comparison study; non-parametric method; parametric method; technical efficiency

\begin{abstract}
Abstrak
Penelitian ini bertujuan untuk mengetahui estimasi efisiensi teknis yang menggunakan teknik parametrik dan nonparametrik dikarenakan kedua metode tersebut masing-masing memiliki kekurangan dan kelebihan. Oleh karena itu, penelitian ini melakukan analisis komparasi di antara tiga metode analisis yaitu Stochastic Frontier Analysis (SFA), Data Envelopment Analysis (DEA), dan Bootstrap $D E A$ terhadap data dari 380 petani karet di Sumatera Selatan. Hasil analisis stochastic frontier menunjukkan bahwa rata-rata skor efisiensi teknis dari kebun sampel adalah 0,72 , yang menunjukkan bahwa rata-rata kebun karet sampel dalam penelitian ini tidak sepenuhnya efisien. Sedangkan hasil dari data envelopment analysis (DEA) yang tidak memperhitungkan randomness menunjukkan bahwa estimasi efisiensi teknis rata-rata sebesar 0,80 , yang menunjukkan bahwa estimasi efisiensi teknis yang dihasilkan dari analisis DEA terlalu tinggi. Kelemahan model DEA tersebut dapat diatasi dengan menerapkan model Bootstrap DEA. Pada analisis Bootstrap DEA, efisiensi teknis rata-rata berkurang menjadi 0,76, yang lebih mendekati nilai efisiensi teknis rata-rata SFA. Hal ini dikarenakan bootstrap DEA dapat menghasilkan interval kepercayaan dan estimasi efisiensi DEA dengan bias yang terkoreksi. Perbedaan kinerja di antara ketiga model-model ini dapat dikaitkan dengan asumsi bahwa perkiraan efisiensi teknis dengan pendekatan non-parametrik DEA hanya bergantung pada efek inefisiensi petani, sedangkan perkiraan efisiensi teknis
\end{abstract}


dengan pendekatan parametrik (SFA) bergantung pada inefisiensi petani dan faktor lain di luar kontrol petani.

Kata kunci: efisiensi teknis; metode nonparametrik; metode parametric; studi komparasi

\section{PENDAHULUAN}

Efisiensi teknis mempertimbangkan kemampuan suatu kebun untuk memaksimalkan output terhadap tingkat input produksi yang digunakan. Secara umum, mengacu pada konsep pengukuran efisiensi berdasarkan gagasan Farrell (1957), maka efisiensi teknis dapat diukur dengan mengestimasi fungsi produksi frontier. Fungsi produksi frontier dapat dikelompokkan menjadi non-parametric frontiers dan parametric frontiers. Dalam mengukur efisiensi produksi, beberapa pendekatan telah dikembangkan seperti Stochastic Frontier Analysis (SFA) yang merupakan metode parametric frontiers dan Data Envelopment Analysis (DEA) yang merupakan metode non-parametric frontiers sudah menjadi model yang populer digunakan.

Sharma et al. (1997) melakukan studi mengenai efisiensi produksi dengan membandingkan perkiraan efisiensi DEA dengan SFA. Mereka berpendapat bahwa DEA lebih dapat diandalkan daripada pendekatan parametrik (SFA) dalam mengukur efisiensi. Mereka menyatakan bahwa DEA merupakan metode nonparametrik yang efektif untuk mengatasi kelemahan metode parametrik (SFA) karena tidak memerlukan bentuk fungsional tertentu. Lee (2005) memperkenalkan SFA, DEA, dan Two-stage DEA. Hasil penelitian menunjukkan bahwa skor efisiensi dari estimasi ketiga metode tersebut memiliki korelasi yang signifikan.

Oren \& Alemdar (2006) dalam kajian efisiensi teknis yang mereka lakukan, untuk mendapatkan hasil estimasi yang dapat diandalkan, mereka membandingkan metode parametrik (SFA) dan nonparametrik (DEA). Hasilnya menunjukkan efisiensi rata-rata SFA adalah 0,54, lebih rendah dari skor efisiensi VRS-DEA $(0,56)$. Theodoridis \& Anwar (2011) melakukan perbandingan antara tiga metode, model SFA, CRS-DEA, dan VRS-DEA, pada 240 kebun di Bangladesh. Hasilnya menunjukkan bahwa terdapat inefisiensi produksi di antara kebun sampel. Mereka menemukan bahwa secara umum hasil estimasi yang dihasilkan metode SFA didukung oleh hasil estimasi yang dihasilkan metode DEA. Hasil korelasi spearman rank menunjukkan bahwa terdapat hubungan yang positif dan signifikan antara pendekatan parametrik dan non-parametrik. Selanjutnya, Zamanian et al. (2013) membandingkan pendekatan DEA dan SFA untuk menghitung tingkat efisiensi teknis, yang mengungkapkan bahwa hasil estimasi SFA lebih rendah daripada hasil estimasi yang diperoleh dengan menggunakan DEA.

Berdasarkan hasil-hasil studi tersebut, dapat disimpulkan bahwa metode SFA dan DEA memiliki kelebihan dan kelemahan masing-masing. Artikel ini bertujuan untuk membandingkan hasil estimasi efisiensi teknis antara metode parametrik (SFA) dan metode nonparametrik (DEA) pada perkebunan karet. Dikarenakan kedua pendekatan sama-sama memiliki kelebihan dan kelemahan, maka dengan menggunakan hanya satu dari pendekatan tersebut untuk menganalisis efisiensi dapat memberikan hasil yang kurang tepat (Lee, 2005). Oleh karena itu, sebaiknya dilakukan evaluasi stabilitas model dengan membandingkan estimasi efisiensi teknis menggunakan pendekatan parametrik (SFA) dan non-parametrik (DEA). Hasil analisis akan memudahkan para pengambil keputusan untuk menggunakan metode-metode tersebut dalam mengidentifikasi efisiensi teknis perkebunan karet.

\section{BAHAN DAN METODE}

Penelitian dilakukan di Provinsi Sumatera Selatan, yaitu pada 11 kabupaten penghasil karet utama di Provinsi Sumatera Selatan, yaitu, Lahat, Musi Banyuasin, Musi Rawas, Muratara, Ogan Komering Ulu (OKU), Ogan Komering Ulu (OKU) Timur, Ogan Komering Ilir (OKI), Ogan Ilir, Muara Enim, Pali, dan Prabumulih. Sasaran populasi penelitian ini adalah rumah tangga karet di Provinsi Sumatera Selatan. Jumlah 
populasi rumah tangga karet diperoleh dari Direktorat Jenderal Perkebunan Kementerian Pertanian (2015). Pemilihan responden dilakukan dengan kombinasi metode purposive, multi stage, dan random sampling. Pada tahap pertama, Provinsi Sumatera Selatan dipilih secara purposive karena merupakan daerah penghasil karet terbesar di Indonesia. Tahap kedua adalah pemilihan purposive di 11 kecamatan, yang juga merupakan daerah dominan penghasil karet di Sumatera Selatan dengan total populasi sebanyak 411.336 petani karet. Kemudian, Krejcie \& Morgan (1970) digunakan untuk menentukan jumlah sampel sebanyak 384 responden. Tahap ketiga, yaitu pemilihan petani karet secara acak sederhana, yang dilakukan di tiap kecamatan dengan perbandingan yang proporsional dengan jumlah penduduk petani karet di tiap kecamatan. Responden petani karet yang tersebar di 11 kabupaten terpilih disajikan pada Tabel 1 .

Tabel 1. Distribusi sampel responden per kabupaten Table 1. Distribution of respondents' samples per district

\begin{tabular}{clcc}
\hline $\begin{array}{c}\text { No } \\
\text { No }\end{array}$ & \multicolumn{1}{c}{$\begin{array}{c}\text { Kabupaten } \\
\text { Districts }\end{array}$} & $\begin{array}{c}\text { Populasi* } \\
\text { Population }\end{array}$ & $\begin{array}{c}\text { Responden terpilih di setiap kabupaten } \\
\text { Selected respondent in each district }\end{array}$ \\
\hline 1 & Lahat & 21,520 & 20 \\
2 & Musi Banyuasin & 69,674 & 65 \\
3 & Musi Rawas & 59,818 & 56 \\
4 & Muratara & 19,120 & 18 \\
5 & Ogan Komering Ulu (OKU) & 22,924 & 21 \\
6 & Ogan Komering Ulu (OKU) Timur & 31,418 & 29 \\
7 & Ogan Komering Ilir (OKI) & 49,532 & 46 \\
8 & Ogan Ilir & 23,895 & 22 \\
9 & Muara Enim & 66,332 & 62 \\
10 & Pali & 36,034 & 34 \\
11 & Prabumulih & 11,069 & 10 \\
\hline & Total & $\mathbf{4 1 1 , 3 3 6}$ & $\mathbf{3 8 4}$ \\
\hline
\end{tabular}

*Sumber: Direktorat Jenderal Perkebunan, 2015

Dikarenakan beberapa data yang dikumpulkan tidak konsisten, maka analisis yang dilakukan hanya pada data yang melibatkan 380 petani. Selanjutnya, survei dilakukan untuk mengumpulkan data yang meliputi data produksi karet dan input produksi yang digunakan oleh petani karet selama tahun produksi 2015, serta data karakteristik sosial ekonomi petani meliputi: umur kepala keluarga petani, total anggota keluarga, tingkat pendidikan petani, kunjungan penyuluhan, pengalaman petani dalam berkebun karet, sistem sadap yang diterapkan petani, serta jenis bahan tanam yang digunakan.

Penelitian ini menerapkan metode parametrik dan non-parametrik untuk mengestimasi efisiensi teknis dikarenakan keduanya masing-masing memiliki kelemahan dan keunggulan. Oleh karena itu, pada penelitian ini dilakukan analisis perbandingan di antara tiga metode yaitu Stochastic Frontier Analysis, Data Envelopment Analysis (DEA), dan Bootstrap
DEA. Mengikuti Zheng (2013), semua metode dikaji menggunakan konsep efisiensi teknis dengan sampel data yang sama serta spesifikasi input dan output yang sama untuk memastikan bahwa SFA, DEA, dan Bootstrap DEA dibandingkan. Mengikuti Theodoridis \& Psychoudakis (2008); Theodoridis \& Anwar (2011), dalam menguji korelasi antara skor efisiensi teknis antara metode SFA, DEA, dan bootstrap DEA, maka dalam penelitian ini digunakan korelasi rank spearman.

\section{Metode Parametrik}

Penelitian ini menerapkan metode parametrik, yaitu dengan pendekatan risiko fleksibel yang diusulkan oleh Kumbhakar (2002) dengan memasukkan risiko (model Just-Pope) ke dalam Stochastic Frontier Analysis (SFA) untuk mengestimasi efisiensi teknis, risiko produksi, dan efek inefisiensi secara simultan, yang menggunakan fungsi translog yang spesifikasinya sebagai berikut: 


$$
\ln y_{i}=\beta_{0}+\sum_{j=1}^{4} \beta_{j} \ln x_{j}+0.5 \sum_{j=1}^{4} \beta_{j j} \ln x_{i}^{2}+\sum_{j=1}^{4} \sum_{k=1}^{4} \beta_{j k} \ln x_{j i} \ln x_{k i}+v_{i}-u_{i}
$$

dimana: $Y_{i}$ merupakan jumlah produksi karet $\left(\mathrm{Kg} /\right.$ th) untuk petani ke- $i$; $\mathrm{X}_{1}$ $=$ weighted trees of rubber $(\mathrm{WRT}) ; \mathrm{X}_{2}=$ jumlah pupuk $(\mathrm{Kg} / \mathrm{th}) ; \mathrm{X}_{3}=$ herbisida (liter $/$ th); $\mathrm{X}_{4}=$ total tenaga kerja (man-hour) per tahun; $\beta_{0}$ adalah konstanta; and $\beta_{\mathrm{j}}$ adalah parameter yang belum diketahui.

$$
\begin{aligned}
& \sigma_{v k}^{2}=\boldsymbol{h}\left(\prod_{k=1}^{3} \alpha_{k} z_{k}\right) \\
& \sigma_{u i}^{2}=q\left(\sum_{i=1}^{7} \delta_{i} w_{i}\right)
\end{aligned}
$$

$v_{\mathrm{i}}$ dan $u_{\mathrm{i}}$ ditentukan pada persamaan (2) dan (3). Maka fungsi resiko dan inefisiensi ditentukan sebagai berikut:

dimana, $Z_{\mathrm{k}}$ adalah variabel yang diestimasi dapat menjelaskan fungsi resiko yang berasal dari ketiga variabel input yaitu, $Z_{1}=$ jumlah pupuk yang digunakan dalam kilogram per tahun (yaitu: urea, $\mathrm{KCl}$, TSP (SP36), atau NPK), $Z_{2}=$ herbisida (liter) per tahun, dan $Z_{3}=$ total tenaga kerja (man-hour) per tahun. $W_{i}$ merupakan vektor karakteristik demografi dan sosial ekonomi petani karet, yaitu $\mathrm{W}_{1}=$ umur petani (tahun), $\mathrm{W}_{2}=$ anggota keluarga (orang), $\mathrm{W}_{3}=$ pendidikan $(0=$ tidak ada pendidikan, $1=S D$, 2= SLTP, 3= SLTA, 4= diploma/universitas), $\mathrm{W}_{4}=$ kunjungan penyuluh $(1=$ mendapat penyuluhan, $\mathrm{O}=$ tidak pernah menerima penyuluhan), $\mathrm{W}_{5}=$ pengalaman berkebun (tahun), $\mathrm{W}_{6}=$ sistem sadap $(1=\mathrm{S} / 2 \mathrm{~d} 2,0=$ selain $\mathrm{S} / 2 \mathrm{~d} 2), \mathrm{W}_{7}=$ bahan tanam $(1=$ klonal, $0=$ non klonal); $a_{i}$ dan $\delta_{j}$ adalah vektor parameter yang akan diestimasi.

\section{Metode Non-Parametrik}

Pada penelitian ini pendekatan nonparametrik yang digunakan adalah metode Data Envelopment Analysis (DEA) konvensional dan bootstrap DEA untuk mengestimasi tingkat efisiensi teknis.

\section{a) Metode Data Envelopment Analysis (DEA)}

Dengan mempertimbangkan kendala-kendala yang bisa terjadi di perkebunan karet, maka model DEA dalam penelitian ini diestimasi dengan menggunakan model Variable Returns to Scale (VRS)-DEA. Kemudian, VRS-DEA yang berorientasi pada output ditentukan sebagai berikut (Coelli et al., 2005):

$$
\begin{aligned}
\operatorname{Max}_{\varphi_{i} \lambda} \varphi & \\
\text { s.t. }-\varphi y_{i}+Y \lambda & \geq 0 \\
x_{i}-X \lambda & \geq 0 \\
\lambda & \geq 0 \\
K 1^{\prime} \lambda & =1
\end{aligned}
$$

dimana, $1 \leq \varphi<\infty$ dan $\varphi$ - 1 mencerminkan peningkatan output yang dapat dihasilkan oleh petani ke-i, dengan jumlah input yang konstan. Skor efisiensi teknis berkisar antara 0 dan 1, yang tercermin dari notasi $1 / \varphi . \quad \mathrm{Y}=$ matriks output untuk kebun karet petani ' $\mathrm{n}$ '; $\mathrm{X}=$ matriks input untuk kebun karet petani ' $n$ '; $y_{i}=$ output untuk kebun karet petani dalam kilogram; $\mathrm{x}_{\mathrm{i}}=$ vektor input $\mathrm{x}_{1 \mathrm{ij}}, \mathrm{x}_{2 \mathrm{ij}}, \mathrm{x}_{3 \mathrm{ij}}$, dan $\mathrm{x}_{\mathrm{ij} 4}$ input dari usaha tani $\mathrm{ke}-\mathrm{i}, \mathrm{x}_{\mathrm{i} 1}=$ weighted rubber trees $(\mathrm{WRT}) ; \mathrm{x}_{\mathrm{i} 2}=$ jumlah pupuk yang digunakan (kilogram); $\mathrm{x}_{\mathrm{i} 3}$ $=$ herbisida yang digunakan (liter); $\mathrm{x}_{\mathrm{i4}}=$ total tenaga kerja (man-hour); $\mathrm{KI}$ ' $\mathrm{\lambda}=1$ adalah kendala konveksitas yang memastikan bahwa inefisiensi suatu kebun hanya dibandingkan dengan kebun lain yang ukurannya sama.

\section{b) Metode Bootstrap DEA}

Simar \& Wilson (2000) mengusulkan prosedur bootstrap untuk mengatasi kelemahan DEA konvensional. Pada tahap pertama, estimasi bootstrap untuk penduga DEA konvensional $\tilde{\boldsymbol{\delta}}(\boldsymbol{x}, \boldsymbol{y})$ dapat dihitung sebagai berikut: 


$$
\operatorname{BÎAS}_{B}(\widetilde{\delta}(x, y))=B^{-1} \sum_{b=1}^{B} \widehat{\delta}_{b}^{\varepsilon}(x, y)-\widehat{\delta}(x, y)
$$

Penelitian ini menerapkan metode integrasi model Just and Pope (J-P) dengan model SFA dengan menggunakan the maximum likelihood estimation yang dianalisis dengan menggunakan software Stata13. Sedangkan untuk menerapkan Data Envelopment Analysis dan Bootstrap $D E A$ dalam mengestimasi efisiensi teknis usahatani karet, penelitian ini menggunakan program $R$ dan paket FEAR.

\section{HASIL DAN PEMBAHASAN}

\section{Perbandingan Hasil Efisiensi Teknis dari Pendekatan Parametrik dan Non- Parametrik}

Dalam pendekatan parametrik, efisiensi teknis diestimasi dengan komponen risiko dimana deviasi dari frontier output berasal dari statistical noise (yaitu kesalahan pengukuran dan faktor yang tidak bisa dikontrol) serta faktor inefisiensi (BravoUreta et al., 2007; Chirwa, 2007; Coelli, et al., 2005). Di sisi lain, dalam pendekatan non-parametrik (DEA konvensional), efisiensi teknis diestimasi tanpa komponen risiko sehingga deviasi/penyimpangan dari output frontier hanya disebabkan oleh inefisiensi (Cascajo \& Monzon, 2012; Coelli et al., 2005; Zbranek, 2013).

Hasil analisis perbandingan menunjukkan bahwa dengan analisis DEA konvensional, terdapat sekitar lebih dari 8 persen kebun karet sampel dapat menggunakan input mereka secara efisien. Oleh karena itu, dengan pendekatan DEA konvensional, para petani responden bisa dikatakan efisien secara teknis. Di sisi lain, dengan pendekatan parametrik (model integrasi SFA dan J-P), semua kebun karet secara teknis tidak efisien karena tidak ada kebun yang dapat menggunakan input produksi secara efisien. Hal ini dikarenakan, pada estimasi dengan pendekatan SFA, efisiensi teknis usahatani karet tidak hanya dipengaruhi oleh ketidakefisienan, tetapi juga kesalahan pengukuran dan faktor yang tidak bisa dikontrol (seperti musim, kebanjiran, atau kebakaran). Demikian pula dengan hasil analisis yang menggunakan pendekatan bootstrap DEA, tidak ditemukan kebun yang mampu mendapatkan skor efisiensi teknisnya 1 (satu). Hal ini dikarenakan esimasi DEA bootstrap juga memperhitungkan statistical noise (Simar \& Wilson, 2000; 2007) (Tabel 2).

Lebih lanjut, hasil analisis menunjukkan bahwa terdapat perbedaan dalam skor efisiensi teknis rata-rata antara pendekatan SFA, bootstrap DEA, dan DEA konvensional. Skor efisiensi rata-rata masing-masing adalah 0,$72 ; 0,76$; dan 0,80 untuk SFA, bootstrap DEA, dan DEA konvensional. Hasil ini menunjukkan bahwa jika dibandingkan dengan SFA yang diintegrasikan dengan spesifikasi risiko yang fleksibel (Bokusheva \& Hockmann, 2006; Kumbhakar, 2002), skor efisiensi teknis yang dihasilkan dari estimasi DEA konvensional terlalu tinggi karena tidak memperhitungkan komponen risiko produksi.

Perbedaan hasil skor efisiensi di antara model-model ini dapat dikaitkan dengan asumsi bahwa perkiraan efisiensi teknis dengan pendekatan DEA nonparametrik hanya bergantung pada efek inefisiensi petani, sedangkan perkiraan efisiensi teknis dalam pendekatan parametrik (SFA) bergantung pada ketidakefisienan petani dan faktor lain di luar kontrol petani. Dalam produksi karet, variabilitas output tidak hanya disebabkan oleh ketidakefisienan, tetapi juga disebabkan oleh cuaca, hama, penyakit, kebakaran, dan kesalahan pengukuran produksi. Oleh karena itu, model SFA lebih tepat untuk diterapkan dalam produksi karet karena memperhitungkan inefisiensi dan kesalahan pengukuran serta faktorfaktor yang tidak dapat dikendalikan dalam mengestimasi fungsi produksi frontier. 
Tabel 2. Distribusi efisiensi teknis yang diestimasi dengan model spesifikasi parametrik dan non-parametrik

Table 2. Distribution of technical efficiency estimated with parametric and non-parametric specification models

\begin{tabular}{|c|c|c|c|c|c|c|}
\hline \multirow[t]{2}{*}{$\begin{array}{l}\text { Kelas Efisiensi } \\
\text { Efficiency Class }\end{array}$} & \multicolumn{2}{|c|}{$\begin{array}{c}\text { Esimasi SFA } \\
\text { SFA estimation }\end{array}$} & \multicolumn{2}{|c|}{$\begin{array}{c}\text { Estimasi } \\
\text { Bootstrap DEA } \\
\text { Bootstrap DEA } \\
\text { Estimation } \\
\end{array}$} & \multicolumn{2}{|c|}{$\begin{array}{c}\text { Estimasi DEA } \\
\text { Konvensional } \\
\text { DEA convenstional } \\
\text { estimation }\end{array}$} \\
\hline & Freq. & $\%$ & Freq. & $\%$ & Freq. & $\%$ \\
\hline$<0.2000$ & 0 & 0.0 & 0 & 0.0 & 0 & 0.0 \\
\hline $0.2001-0.3000$ & 1 & 0.3 & 0 & 0.0 & 0 & 0.0 \\
\hline $0.3001-0.4000$ & 9 & 2.4 & 0 & 0.0 & 0 & 0.0 \\
\hline $0.4001-0.5000$ & 32 & 8.4 & 9 & 2.4 & 4 & 1.1 \\
\hline $0.5001-0.6000$ & 53 & 13.9 & 38 & 10.0 & 28 & 7.4 \\
\hline $0.6001-0.7000$ & 85 & 22.4 & 64 & 16.8 & 62 & 16.3 \\
\hline $0.7001-0.8000$ & 82 & 21.6 & 86 & 22.6 & 72 & 18.9 \\
\hline $0.8001-0.9000$ & 45 & 11.8 & 137 & 36.1 & 115 & 30.3 \\
\hline 0.9000-0.9999 & 73 & 19.2 & 46 & 12.1 & 66 & 17.4 \\
\hline 1.0000 & 0 & 0.0 & 0 & 0.0 & 33 & 8.7 \\
\hline Total & 380 & & 380 & & 380 & \\
\hline Rata-rata & 0.72 & & 0.76 & & 0.80 & \\
\hline Minimum & 0.30 & & 0.44 & & 0.46 & \\
\hline Maksimum & 0.99 & & 0.95 & & 1.00 & \\
\hline Std. Deviasi & 0.17 & & 0.12 & & 0.13 & \\
\hline
\end{tabular}

(Sumber: Estimasi penulis)

Kendati demikian, kelemahan DEA konvensional dapat diatasi dengan menerapkan bootstrap DEA, yang hasil estimasinya mendekati skor efisiensi SFA.

Dalam literatur, tidak banyak studi mengenai efisiensi yang menerapkan analisis perbandingan SFA dan DEA. Selain itu, sebagian besar memiliki hasil yang bertentangan. Hasil setelah dilakukan perbandingan antara metode SFA dan DEA konvensional dalam penelitian ini sejalan dengan hasil yang diperoleh oleh Wadud (2003). Dalam Wadud (2003), estimasi skor rata-rata efisiensi teknis berdasarkan DEA konvensional $(\mathrm{TE}=0,91)$ lebih tinggi daripada yang didasarkan pada SFA $(\mathrm{TE}=$ 0,80 ), dan analisis SFA menunjukkan adanya variabilitas yang lebih besar dalam skor efisiensi teknis dibandingkan skor efisiensi DEA konvensional. Hasil analisis Wadud (2003), dapat menegaskan hasil analisis pada penelitian ini.

\section{Analisis Koefisien Korelasi Rank Spearman}

Tabel 3 menunjukkan bahwa koefisien korelasi Rank Spearman dari skor efisiensi teknis yang diperoleh dari analisis SFA, Bootstrap DEA, dan DEA konvensional. Hasil pada Tabel 3 menunjukkan bahwa koefisien korelasi efisiensi antara model SFA, Bootstrap DEA, dan DEA konvensional adalah positif dan signifikan pada tingkat 1 persen. Korelasi yang paling kuat terjadi diantara skor efisiensi model DEA tradisional dan DEA Bootstrap. Korelasi paling lemah diperoleh antara skor efisiensi SFA dan DEA konvensional.

Secara keseluruhan, hasil analisis dalam penelitian ini menunjukkan bahwa estimasi skor efisiensi teknis antara pendekatan SFA, Bootstrap DEA, dan DEA konvensional tidak jauh berbeda. Hasil penelitian menunjukkan bahwa kinerja model SFA, Bootstrap DEA, dan DEA tradisional sebanding. Hal ini ditunjukkan oleh korelasi positif dan sangat signifikan dari skor efisiensi di antara model-model pendekatan ini. Dengan demikian, para pengambil keputusan dapat merasa mudah ketika memperkirakan efisiensi teknis petani karet dengan menggunakan metodemetode ini. 
Tabel 3. Koefisien korelasi spearman antara pendekatan parametrik dan non-parametrik Table 3. Spearman rank correlation coefficients between parametric and non-parametric approaches

\begin{tabular}{lccc}
\hline Skor Efisiensi Efficiency & TE SFA & TE bootstrap DEA & TE DEA konvensional \\
\multicolumn{1}{c}{ score } & $T E_{\text {SFA }}$ & $T E_{\text {bootstrap DEA }}$ & TE Conventional DEA \\
\hline TE SFA $_{\text {TE }}^{\text {bootstrap DEA }}$ & 1.000 & $0.579^{* * *}$ & $0.546^{* *}$ \\
TE DEA konvensional $^{* * *}$ & $0.579^{* * *}$ & 1.000 & $0.973^{* * *}$ \\
\hline
\end{tabular}

Catatan: *** korelasi signifikan pada level 0,01

(Sumber: Estimasi penulis)

\section{KESIMPULAN}

Hasil analisis SFA menunjukkan bahwa rata-rata skor efisiensi teknis dari kebun sampel adalah 0,72 , yang menunjukkan bahwa usahatani karet dalam penelitian ini tidak sepenuhnya efisien. Sedangkan data envelopment analysis (DEA) konvensional yang tidak memperhitungkan statistical noise/ randomness menghasilkan estimasi skor efisiensi teknis rata-rata sebesar 0,80, yang menunjukkan bahwa perkiraan efisiensi teknis yang dianalisis menggunakan DEA konvensional terlalu tinggi dan bias. Namun, kelemahan DEA konvensional ini dapat diatasi dengan menerapkan Bootstrap DEA. Dari hasil analisis yang menggunakan Bootstrap DEA, skor efisiensi teknis rata-rata dapat berkurang menjadi 0,76, yang nilainya lebih dekat dengan skor efisiensi teknis rata-rata yang dihasilkan dari analisis SFA. Hal ini dikarenakan bootstrap DEA telah menghasilkan interval kepercayaan dan estimasi skor efisiensi DEA yang biasnya sudah terkoreksi. Perbedaan kinerja di antara model SFA, Bootstrap DEA, dan DEA konvensional ini dapat dikaitkan dengan asumsi bahwa estimasi efisiensi teknis dengan pendekatan DEA hanya bergantung pada efek inefisiensi petani, sedangkan estimasi efisiensi teknis dengan pendekatan SFA bergantung pada inefisiensi petani dan faktor lain di luar kontrol petani.

\section{DAFTAR PUSTAKA}

Bravo-Ureta, B.E., Solis, D., Lopez, V.H.M., Maripani, J.F., Thiam, A., \& Rivas, T. (2007). Technical efficiency in farming: a meta-regression analysis. Journal of Production Analysis, 27, 5772.
Bokusheva, R., \& Hockmann, H. (2006). Production risk and technical inefficiency in Russian agriculture. European Review of Agricultural Economics, 33(1), 93-118.

Cascajo, R., \& Monzon, A. (2012). Analysis of the technical efficiency of urban bus service in Spain based on SBM models. International Scholarly Research Network. ISRN Civil Engineering, 1-13.

Chirwa, E.W. (2007). Sources of technical efficiency among smallholder maize farmers in Southern Malawi. AERC Research Paper, RP_172. Nairobi: African Economic Research Consortium.

Coelli, T.J., Rao, D.S.P., O'Donnell, C.J., \& Battese, G.E. (2005). An Introduction to Efficiency and Productivity Analysis. $2^{\text {nd }}$ ed. New York, USA: Springer Science+ Business Media, Inc.

Direktorat Jenderal Perkebunan. (2015). Tree Crop Estate Statistics of Indonesia (Statistik Perkebunan Indonesia). Rubber (Karet) 2014-2016. Jakarta: Direktorat Jenderal Perkebunan.

Farrell, M. J. (1957). The measurement of productive efficiency. Journal of the Royal Statistical Society, 120(3), 253290.

Kumbhakar, S.C. (2002). Specification and estimation of production risk, risk preferences and technical efficiency. American Journal of Agricultural Economics, 84, 8-22.

Krejcie, R.V., \& Morgan, D.W. (1970). Determining sample size for research activities. Educational Psychological Measured, 30, 607-610. 
Lee, J.Y. (2005). Comparing SFA and DEA methods on measuring production efficiency for forest and paper companies. Forest Products Journal, 55(7/8), 51-56.

Oren, M.N., \& Alemdar, T. (2006). Technical efficiency analysis of tobacco farming in South Eastern Anatolia. Turkey Journal of Agriculture, 30, 165-172.

Sharma, K.R., Leung, P., \& Zalenski, H.M. (1997). Productive efficiency of the swine industry in Hawaii: Stochastic frontier vs. Data Envelopment Analysis. Journal of Productivity Analysis, 8, 447-459.

Simar, L., \& Wilson, P.W. (2000). A general methodology for bootstrapping in nonparametric frontier models. Journal of Applied Statistics, 27(6), 779-802.

Simar, L., \& Wilson, P.W. (2007) Estimation and inference in two-stage, semiparametric models of production processes. Journal of econometrics, 136, 31-64.

Theodoridis, A.M., \& Psychoudakis, A. (2008). Efficiency measurement in Greek Dairy farms: Stochastic frontier vs Data envelopment analysis. International Journal of Economics Sciences and Applied Research, 2, 5366.
Theodoridis, A. M., \& Anwar, M.Md. (2011). A comparison of DEA and SFA methods: A case study of farm households in Bangladesh. The Journal of Developing Areas, 45, 95-110.

Wadud, M.A. (2003). Technical, allocative, and economic efficiency of farms in Bangladesh: A stochastic frontier and DEA approach. Journal of Developing Areas, 37(1), 109-126.

Zamanian, G.R., Shahabinejad, V., \& Yaghoubi, M. (2013). Application of DEA and SFA on the measurement of agricultural technical efficiency in MENA countries. International Journal of Applied Operational Research, 3(2), 43-51.

Zbranek, P. (2013). Data Envelopment Analysis as a tool for evaluation of employees' performance. Acta Oeconomica et Informatika, XVI(1), 1221.

Zheng, W. (2013). Efficiency measurement. A methodological comparison of parametric and non-parametric approaches [tesis]. Inggris: University of Bradford. 